\title{
Hepcidin Mimetic PTG-300
}

National Cancer Institute

\section{Source}

National Cancer Institute. Hepcidin Mimetic PT G-300. NCI Thesaurus. Code C162883.

An injectable peptide mimetic of hepcidin (hepcidin antimicrobial peptide; HAMP; putative liver tumor regressor; PLT R; liver-expressed antimicrobial peptide 1; LEAP-1) with potential use in the treatment of iron deficiency anemia and iron overload secondary to hematologic disorders. Upon administration, the hepcidin mimetic PTG-300 mimics endogenous hepcidin, a protein primarily produced in hepatocytes, and increases hepcidin levels. As hepcidin plays a key role in the homeostasis of systemic iron, PT G-300 may serve to normalize iron levels. Low levels of endogenous hepcidin are associated with iron overload secondary to excessive absorption of iron as seen in beta thalassemia and paradoxically with iron deficiency anemia. 